\title{
Endoplasmic Reticulum Stress, Pancreatic $\beta$-Cell Degeneration, and Diabetes
}

\author{
Feroz R. Papa \\ Department of Medicine, The Diabetes Center, The Lung Biology Center, and The California Institute for \\ Quantitative Biosciences, University of California, San Francisco, San Francisco, California 94143-2520 \\ Correspondence: frpapa@medicine.ucsf.edu
}

Overwhelming of protein folding in the endoplasmic reticulum (ER)—referred to as "ER stress" - activates a set of intracellular signaling pathways termed the unfolded protein response (UPR). Beneficial outputs of the UPR promote adaptation in cells experiencing manageably low levels of ER stress. However, if ER stress reaches critically high levels, the UPR uses destructive outputs to trigger programmed cell death. Genetic mutations in various UPR components cause inherited syndromes of diabetes mellitus in both rodents and humans, implicating the UPR in the proper functioning and survival of pancreatic islet $\beta$ cells. Markers of chronically elevated ER stress, terminal UPR signaling, and apoptosis are evident in $\beta$ cells in these rare disorders; these markers are similarly present in islets of human patients with common forms of diabetes. These findings promise to enhance our molecular understanding of human diabetes significantly and may lead to new and effective therapies.

\begin{abstract}
bout one-third of the proteome consists of Asoluble and transmembrane proteins that use the secretory pathway to localize to intracellular organelles, the plasma membrane, or the extracellular space (Gething and Sambrook 1992; Gaut and Hendershot 1993). During their biogenesis, these secretory proteins are first injected into the endoplasmic reticulum (ER), wherein they must fold to their native conformations. Within the ER, these proteins also undergo various posttranslational modifications, including glycosylation and disulfide bond formation; abundant ER-resident enzymes catalyze these reactions on the secretory protein clients. Molecular chaperones in the ER cyclically bind and release the client proteins as they fold to their native shapes, shielding them from ag-
\end{abstract}

gregation. Glycosylating enzymes add and trim glycan groups, and oxido-reductases catalyze disulfide bond formation (Sevier and Kaiser 2002; Tu and Weissman 2004). Together, these enzymatic processes maximize the probability that secretory proteins are properly folded, modified, and assembled into multiprotein complexes in the ER before they traffic farther downstream in the secretory pathway.

The effort of these protein-folding machines notwithstanding, a substantial fraction of secretory proteins normally fails to fold properly in the ER. Because secretory proteins often mediate crucial signaling roles (e.g., cell surface receptors or polypeptide hormones), incompletely folded forms are not tolerated, and instead are disposed of through discriminating

Editors: Jeffrey A. Bluestone, Mark A. Atkinson, and Peter Arvan

Additional Perspectives on Type I Diabetes available at www.perspectivesinmedicine.org

Copyright (C) 2012 Cold Spring Harbor Laboratory Press; all rights reserved; doi: 10.1101/cshperspect.a007666

Cite this article as Cold Spring Harb Perspect Med 2012;2:a007666 
F.R. Papa

quality-control systems. Through a process called ER-associated degradation (ERAD), unfolded proteins are removed to the cytosol for subsequent ubiquitylation and degradation by the 26S proteasome (McCracken and Brodsky 2003; Meusser et al. 2005; Smith et al. 2011). ER unfolded secretory proteins are also disposed of through autophagy (Kaniuk et al. 2007; Yorimitsu and Klionsky 2007). These quality-control processes are highly stringent, and when they operate properly, optimal protein products are produced and secreted by the cell.

However, cells frequentlyencounter environmental challenges during which protein-folding demand in the ER exceeds capacity. During such imbalanced states of "ER stress," secretory proteins start to accumulate in incompletely modified and unfolded forms at significant levels within the ER. Diverse challenges, both physiological and pathological, can provoke ER stress. For instance, ischemia causes nutrient and oxygen deprivation to deplete cellular energy stores, which, in turn, compromises the energy-intensive processes of ER protein modification and folding (Kaufman 2002). ER stress appears to occur naturally in cells that undergo differentiation into specialized professional secretory types (e.g., terminal differentiation of B lymphocytes into immunoglobulin-producing plasma cells) (Reimold et al. 2001).
Overproduction of secretory proteins may in and of itself generate ER stress; this is especially true for mutant forms of secretory proteins that are particularly difficult to fold. For instance, pancreatic islet $\beta$ cells sustain a high rate of insulin production and secretion, which can rise even greater in stressed states that are either acquired, or caused by genetic mutations (described in detail below).

The presence of unfolded proteins in the ER during stress triggers a set of intracellular signaling pathways called the unfolded protein response (UPR) (Bernales et al. 2006). Cells are alerted to the presence of unfolded proteins within the ER by three widely expressed ER transmembrane signaling proteins called protein kinase RNA (PKR)-like ER kinase (PERK), activating transcription factor-6 (ATF6), and inositol-requiring enzyme-1 (IRE1 $\alpha$ ) (Fig. 1) (Tirasophon et al. 1998; Harding et al. 1999; Yoshida et al. 2000). These three signaling proteins become activated through direct and/ or indirect binding of unfolded proteins (Credle et al. 2005; Zhou et al. 2006; Gardner and Walter 2011). Combinatorial signals from IRE1 $\alpha$, PERK, and ATF6 initially trigger transcriptional programs that up-regulate genes encoding many of the aforementioned ER chaperones, oxidoreductases, and ERAD components (Travers et al. 2000). By increasing the

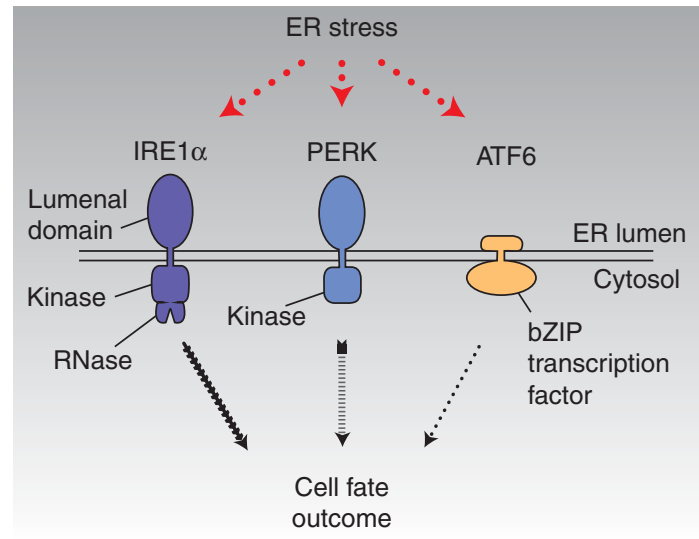

Figure 1. Proximal sensors of endoplasmic reticulum (ER) stress-IRE1 $\alpha$, ATF6, PERK. Combinatorial outputs from these three ER transmembrane sensors are integrated over time to determine cell fate outcomes under ER stress. 
complement of ER protein-folding and qualitycontrol enzymes, the UPR enhances the cell's capacity to sustain protein secretion during times of high demands. The UPR also imposes a transient translational block during ER stress, thereby concentrating available resources to allow preexisting proteins to fold before new ones are made. If these adaptive UPR outputs are successful, the decline in levels of unfolded proteins causes UPR signaling to wane as homeostasis is restored (Merksamer et al. 2008). Thus, the physiological outputs of the UPR in cells that experience manageable levels of ER stress promote homeostasis.

However, if ER stress persists at irremediably high levels, the UPR switches its physiological outputs from promoting adaptation to instead promoting self-destruction; this culminates in programmed cell death, usually through apoptosis (Fig. 2). The commitment to cell destruction appears to occur as a consequence of highlevel/chronic activation of the UPR operating in alternate modes - we refer to this condition as a "terminal UPR." During terminal UPR signaling, cells may transition through intermediate dysfunctional states, before finally undergoing programmed cell death. For instance, some cell types become dedifferentiated or chronically inflamed under irremediable ER stress (Zhang et al. 2006). Stress levels in the ER are reflected through the activation levels of IRE1 $\alpha$, PERK, and ATF6; therefore, these upstream sensors are centrally poised to receive and transmit the information needed by the cell to commit in a binary manner either to adaptation or to selfdestruction.

By relegating highly stressed cells to apoptosis, multicellular organisms may be exercising an extreme but definitive form of protein quality control. At the cost of culling some irreversibly stressed cells, multicellular organisms may derive physiological benefits. Just as reasonably, if the apoptotic process becomes too vigorous, organisms may suffer organ failure caused by an insufficient mass of functioning cells. This particular point is vividly on display in many informative genetic syndromes of diabetes mellitus caused by the degeneration of insulin-producing pancreatic islet $\beta$ cells in the face of irremediable ER stress- these are discussed next.

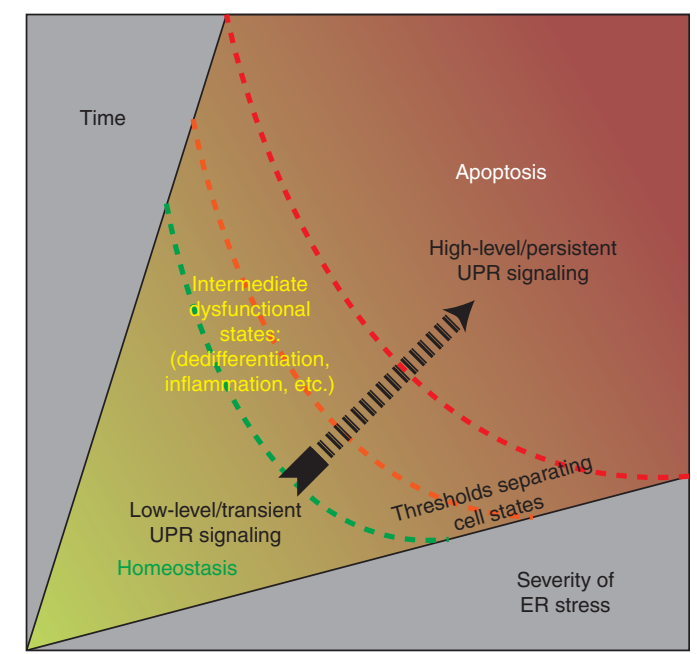

Figure 2. Divergent cell fates result from both the magnitude and duration of ER stress signaling. Adaptive UPR outputs can contain low levels of ER stress by reducing the concentration of unfolded proteins in the ER. However, continued activation of the UPR sensors indicates the inability to reestablish homeostasis. Depending on the time and severity of stress experienced by the cell, thresholds separating distinct cell states are crossed. If ER stress is unrelieved, UPR signaling morphs to terminal states, promoting cell dedifferentiation and inflammation and eventually triggering apoptosis. 
F.R. Papa

\section{UPR MUTATIONS CAUSE RARE, INHERITED DIABETIC SYNDROMES}

Pancreatic islet $\beta$ cells are specialized cells that produce and secrete the hormone insulin in response to increases in ambient blood glucose levels. By setting off a signal transduction cascade when insulin binds its receptor on insulinresponsive cells in peripheral tissues, glucose enters these target cells, causing energy production, and removing the stimulus for further insulin release as blood glucose levels normalize. This tight glucostatic cycle is dysregulated in the disease diabetes mellitus, ultimately because of an insufficient mass of functioning $\beta$ cells to produce the amounts of insulin needed in the fasted and postprandial states for normoglycemia.

$\beta$ cells contain highly developed ERs because they are charged with the task of producing insulin continuously during their lives. It has been estimated that each $\beta$ cell produces approximately 1 million molecules of insulin every minute (Scheuner and Kaufman 2008). Insulin biogenesis requires a complex series of molecular biosynthetic events that are initiated in the ER (Steiner 2000). The insulin precursor, prepro-insulin, is cotranslationally translocated into the ER lumen, whereupon its signal sequence is removed, generating pro-insulin. ERresident oxido-reductases catalyze formation of three intramolecular disulfides in pro-insulin to help it fold to its native shape. The importance of oxidative folding for structural maturation and trafficking of pro-insulin to the Golgi and secretory granules is shown vividly by the "Akita" mouse mutant, which cannot perform this process. The Akita mouse expresses a pro-insulin variant gene, Ins2 (C96Y) - "Akita" insulin. Because Ins2 (C96Y) lacks a cysteine needed to form one of the intramolecular disulfide bonds that helps it fold the ER, it can progress no farther than this organelle in the secretory pathway (Wang et al. 1999; Ron 2002; Izumi et al. 2003). In contrast, wild-type pro-insulin folds oxidatively to its native state in the ER and is properly trafficked to downstream Golgi and secretory granules, where it is further processed by endoproteases that remove its C-peptide to generate mature insulin (Liu et al. 2005).
Akita is the first of several textbook examples considered that link ER stress to the death of $\beta$ cells and diabetes (see Fig. 3). Diabetes in the Akita mouse is not caused directly by reduction of mature insulin levels. Despite retaining three normal insulin gene copies (mice possess two distinct insulin-encoding genes), the mice instead suffer from insufficient insulin production secondary to $\beta$-cell loss. Akita insulin causes a toxic gain-of-function diabetic syndrome (Wang et al. 1999). By accumulating in the ER as a conformationally altered immature species, Akita insulin may act as a "proteotoxin" that exhausts homeostatic UPR outputs, and instead triggers a terminal UPR (Ron 2002). This causes $\beta$ cells in the Akita mouse to deterministically enter the apoptotic pathway, leading diabetes to develop predictably $\sim 4 \mathrm{wk}$ after birth (Oyadomari et al. 2002). Rare infantile diabetes-causing Akita-like insulin mutations have been recently described in humans (Stoy et al. 2007). Intriguingly, genetic removal of a downstream pro-apoptotic UPR transcription factor called C/EBP homologous protein $(\mathrm{CHOP})$ ameliorates $\beta$ cell loss and diabetes in the Akita background, emphasizing the central role the terminal UPR plays in $\beta$-cell degeneration (Oyadomari et al. 2002).

Another striking example of ER stress and UPR dysregulation causing diabetes is seen in the Perk knockout mice. Homozygous deletion in mice of the gene encoding the UPR sensor PERK causes massive and rapid $\beta$-cell apoptosis, leading to infantile diabetes (Delepine et al. 2000; Harding et al. 2000b). Perk knockout mice also develop pancreatic exocrine insufficiency and show growth defects early in life. These defects are believed to be secondary to dysfunction and death of several different important professional secretory cell types; intriguingly, diabetes mellitus is one of the earliest and most severe phenotypes in the mutant animals. A rare human diabetic syndrome caused by PERK-null gene mutations (called Wolcott-Rallison syndrome) phenocopies many of the features of the Perk knockout animals.

Underlying mechanisms of cell degeneration due to PERK deficiency are understood in considerable detail, although many important 
ER Stress, Pancreatic $\beta$-Cell Degeneration

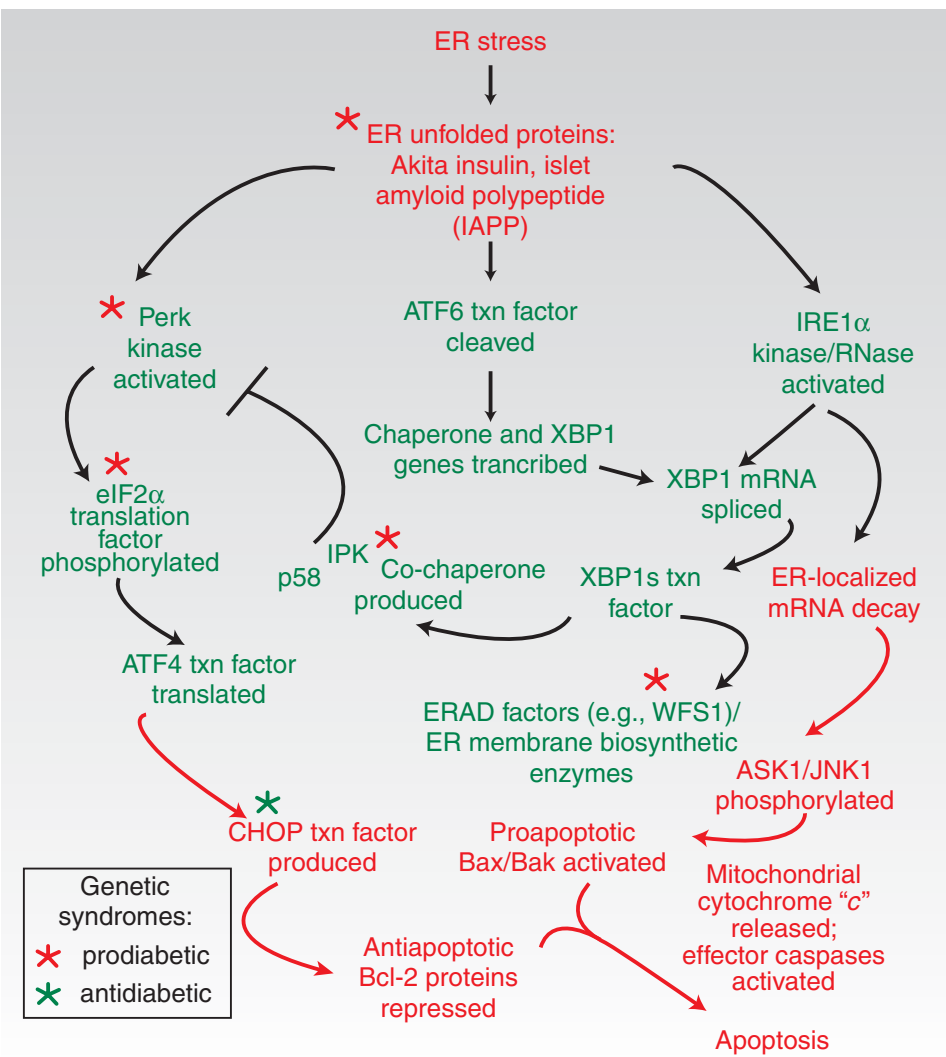

Figure 3. UPR players and effects of gene mutations on $\beta$-cell degeneration and diabetes. Early adaptive events are shown in green, and subsequent pro-apoptotic events are shown in red. A point of no return is crossed when mitochondria are permeabilized by the terminal gatekeepers Bax and Bak to liberate cytochrome " $c$ " - mitochondrial outer membrane permeabilization (MOMP). Gene mutations promoting diabetes (red asterisks) remove adaptive players in the UPR; downstream removal of pro-apoptotic CHOP is protective (green asterisk).

questions remain. PERK is an ER transmembrane kinase that dimerizes under ER stress. Dimerization causes the kinase domains to trans-autophosphorylate, which consequently increases phosphorylation activity against its downstream substrate, the eIF2 $\alpha$ translation initiation factor. Activated PERK phosphorylates eIF2 $\alpha$ on the Ser-51 residue, which causes translation to cease globally because it depletes the eIF2 - GTP - Met-tRNA i $_{\mathrm{i}}$ complex needed to initiate cap-dependent mRNA translation. It has been proposed that because of the absence of PERK, $\beta$ cells cannot properly attenuate translation to match ER protein-folding capacity. As a consequence, they suffer deposition of unfolded proteins in the ER (Harding et al. 2000b). Consistent with this notion, the ERs of $\beta$ cells in Perk ${ }^{-/-}$mice are distended with electron-dense proteinaceous material, and the islets show a high rate of apoptosis. Additionally, there appears to be a marked decline in $\beta$-cell proliferation early in neonatal life in the knockout animals. The inability to compensate for increased rates of apoptosis through increasing $\beta$-cell proliferation is likely to be an important component in the endocrine pancreatic failure in the Perk ${ }^{-1-}$ animals (Gupta et al. 2009).

Translation attenuation through phosphorylation of eIF $2 \alpha$ also occurs through other kinases that sense different upstream stresses. For instance, GCN2 and PKR are two widely expressed eIF $2 \alpha$ kinases that become active under amino acid deprivation and accumulation of double-stranded RNAs, respectively. GCN2 is 
F.R. Papa

the most conserved of eIF2 $\alpha$ kinases because it is the only one present in unicellular eukaryotes. Indeed, PERK appears to have evolved in metazoans through duplication and rearrangement of the genes encoding GCN2 and the most ancient UPR sensor, IRE1 $\alpha$. PERK signaling may normally be used as a glucose-sensing mechanism to prime the secretory apparatus for the upcoming synthesis and structural maturation of pro-insulin in response to changes in glucose levels in the blood (Trusina et al. 2008). However, the strategy of limiting translation is fraught with the danger that should upstream stress remain unrelieved, cells may never resume translation to levels needed to recover viability. Thus, there are safety valves that extinguish PERK signaling after a time window has elapsed.

The importance for glycemic control of an escape from this global translational block is seen in two mouse mutant models: (1) A knock-in mouse mutant expressing an unphosphorylatable eIF2 $\alpha$ version (S51A) develops a severe wasting syndrome shortly after life due to arrested hepatic gluconeogenesis in the homozygote (Scheuner et al. 2001), and a milder insulin-resistant hyperglycemic syndrome in the heterozygote (Scheuner et al. 2005). (2) $\mathrm{p} 58^{\mathrm{IPK}}$ is a co-chaperone produced several hours after the UPR has been initiated. $\mathrm{p} 58^{\mathrm{IPK}}$ may help to close a timing loop necessary to turn off the UPR by inhibiting eIF $2 \alpha$ kinases, including PERK. Homozygous loss of the gene encoding $\mathrm{p} 58^{\mathrm{IPK}}$ causes diabetes (Ladiges et al. 2005; Oyadomari et al. 2006; Laybutt et al. 2007). By the time $\mathrm{p} 58^{\mathrm{IPK}}$ is produced, if cells have not yet returned to homeostasis, the UPR may switch from promoting homeostasis to an apoptotic mode. In the absence of $\mathrm{p} 58^{\mathrm{IPK}}$, a continued translational block through PERK may signal a frustrated UPR cycle. Together, the $\mathrm{p} 58^{\mathrm{IPK}}$, eIF2 $\alpha$ (S51A), and PERK genetic models offer fascinating insights into the importance of temporal control of UPR signaling for cell fate.

Although its most proximal effect is in regulating translation under ER stress, PERK also promotes transcriptional changes through the downstream UPR transcription factor ATF4, which becomes preferentially translated even as cap-dependent translation declines globally. It is known that many ATF4 gene targets have anti-oxidant functions in the cell (Harding et al. 2000a). Thus, because ATF4 responses are abrogated in the Perk ${ }^{-/-}$animals, it is unclear to what degree the removal of these potentially cytoprotective outputs contributes to the diabetic phenotype in the mice. Indeed, mouse embryonic fibroblasts derived from either Perk $^{-/-}$or Atf $4^{-/-}$mice appear to be basally under high oxidative stress_-defined here as accumulation of reactive oxygen species (ROS). It has been estimated generally that $\sim 25 \%$ of cellular ROS originates from the ER through the process of oxidative protein folding. Acting through protein disulfide isomerases (PDIs), the ERO1 oxido-reductase transfers electrons from cysteine sulfhydryl groups on ER-translocated proteins to molecular oxygen, stoichiometrically generating $\mathrm{H}_{2} \mathrm{O}_{2}$ as an ROS byproduct. For professional secretory cells, ROS production by the ER may be even higher. Because the $\beta$-cell ER needs to produce three disulfides for each molecule of pro-insulin it synthesizes (i.e., 3 million disulfides/min per cell), a large load of ROS is necessarily produced that needs to be continually disposed of. Futile disulfide bond formation, due to an unpaired cysteine as in Akita insulin, is another source of elevated ROS from the ER. It is also known that $\beta$ cells normally express limiting levels of cellular enzymes that detoxify ROS (glutathione peroxidase and catalase) (Lenzen et al. 1996), perhaps making $\beta$ cells especially susceptible to oxidative stress. An ER-resident ROS-degrading enzyme called PRDX4 that uses $\mathrm{H}_{2} \mathrm{O}_{2}$ generated by ERO1 in a salvage pathway to promote oxidation of secretory clients was recently described (Zito et al. 2010); intriguingly, overexpression of PRDX4 in the $\beta$ cell protects against a form of experimental diabetes caused by the $\beta$-cell toxin streptozotocin (STZ) (Ding et al. 2010).

Another genetic example of ER stress-induced diabetes comes from the $W f_{s} 1^{-/-}$mouse, and in humans with Wolfram syndrome. WFS1 is an ER transmembrane protein whose loss causes early-onset diabetes, neurodegeneration, and optic and auditory defects (Riggs et al. 2005). WFS1 protein is widely expressed in 
diverse tissues and is thought to aid protein assembly and ERAD (Fonseca et al. 2005), as well as control processing of the UPR sensor ATF6 (Fonseca et al. 2005, 2010). As with PERK and $\mathrm{p} 58^{\mathrm{IPK}}$ deficiency, the earliest defects manifest in pancreatic $\beta$ cells.

The aforementioned examples amply illustrate the principle that ER unfolded protein accumulation and removal of key UPR functions promote apoptosis in $\beta$ cells to cause diabetes. These experimental genetic syndromes and rare naturally occurring diseases link $\beta$-cell degeneration to diabetes through mechanisms of ER stress and dysregulated UPR activity (summarized in Fig. 3); we predict that more such examples will be found as newer mouse UPR genetic models are generated and human genome sequencing efforts expand. These fascinating experimental and rare inherited disorders manifest with near-complete penetrance. The commonality of phenotype begs the question of why pancreatic $\beta$ cells should be so disproportionately affected in UPR mutants (as compared with other tissues). Some thoughts on this matter are offered in the next section on more widespread forms of human diabetes. Indeed, the excitement of these experimental findings proceeds from logically extending many of the key concepts to ask whether lessons learned can advance our understanding of common human diabetic syndromes - that is, types 1 and 2 and gestational diabetes. It would be exciting if the fundamental knowledge gained regarding UPR signaling can successfully be applied and translated to these human diabetes syndromes. Importantly, it may also allow rational therapeutic assaults to be mounted, because durable treatments for these diseases have remained elusive. The application of these principles for understanding common forms of human diabetes is considered next.

\section{ER STRESS AND THE UPR IN COMMON FORMS OF HUMAN DIABETES}

We predict that the rare ER stress disease models discussed above will be powerfully informative for understanding underlying mechanisms of $\beta$-cell functional shutdown and degeneration in common human diabetes. As individual units, the functioning $\beta$ cells in a pancreas may experience increasing and unresolvable ER stress as they compensate for neighboring $\beta$ cells that have become dysfunctional through disease and aging. Studies confirm that $\beta$ cells of mice may already be functioning (even in healthy states) at levels of UPR activation that are significantly greater than in other professional secretory cells (Iwawaki et al. 2004). Therefore, without a wide margin for further homeostatic adjustment, $\beta$ cells could quickly cross a threshold that puts them at risk for dedifferentiation and apoptosis through a terminal UPR.

Thus, as per-cell ER stress levels rise and terminal UPR outputs stochastically cause the death of individual cells, vicious cycles leading inexorably on to whole pancreatic organ failure should set in. In this unifying scheme (Fig. 4), the upstream stresses differ for types 1 and 2 diabetes, but the downstream outcomes will be common: For type 1 diabetes (DM1), a disease that results from autoimmune attack by $\mathrm{T}$ lymphocytes against $\beta$ cells, as $\beta$-cell function degenerates, remaining cells in islets would necessarily have to compensate by overworking and may themselves experience critical thresholds of ER stress. Thus, UPR-mediated apoptosis from within the $\beta$ cell may synergize with pro-death processes initiated by autoimmune attack from without through cells of the innate and adaptive immune system.

For type 2 diabetes (DM2), a disease provoked by peripheral insulin resistance, $\beta$ cells are forced to compensate by increasing insulin production to abnormally high levels (Karam et al. 1963). Successful $\beta$-cell compensation may prevent progression to frank diabetes, but in some insulin-resistant patients, the dysfunction and death of enough $\beta$ cells (roughly half of the original $\beta$-cell mass) occurring over many years may lead to a tipping point and organ failure beyond which normoglycemia cannot be maintained. The inability to compensate for declining numbers of $\beta$ cells through cell proliferation in some populations may contribute to this process. Interestingly, although a pre-diabetic (compensated) state may exist stably for years, progression to frank type diabetes occurs on a 
F.R. Papa

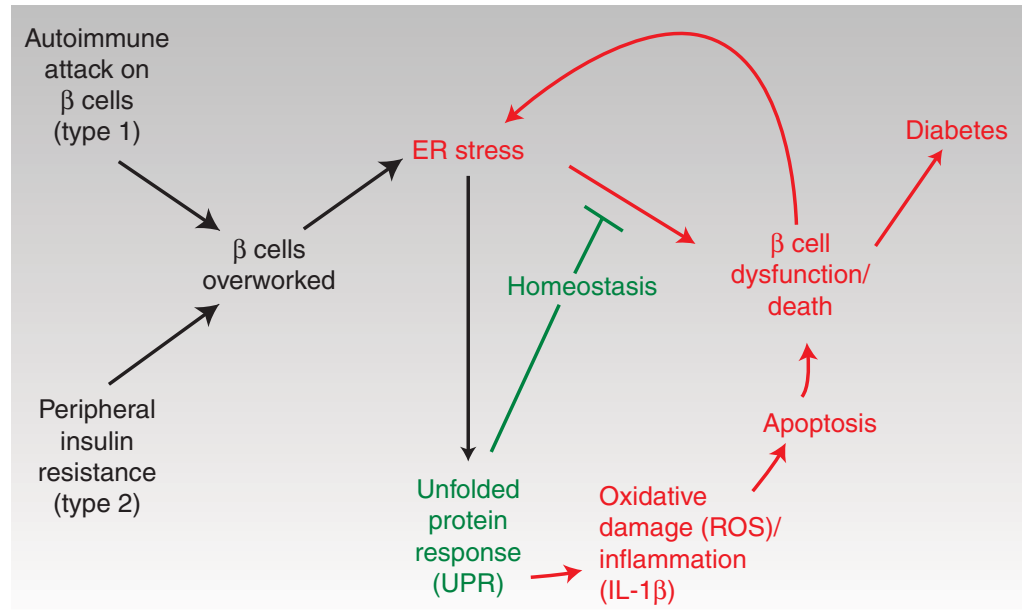

Figure 4. Conjectural scheme for a central role of ER stress and divergent UPR signaling in human diabetes (both types 1 and 2). See text for details.

much shorter time scale (perhaps weeks) (Stefan et al. 1982; Weir and Bonner-Weir 2004), indicating that an "acute-on-chronic" organ shutdown may be occurring; the often dramatic initial presentation of type 1 diabetes is also consistent with such dynamics. Intriguingly, both disorders may have a long metastable period of failing compensation, which perhaps could be exploited through intervention in those at risk (as in the Diabetes Prevention Program, DPP) (Knowler et al. 2002). Although type 1 diabetes has traditionally been regarded primarily as a discrete and homogeneous disorder (when compared with the greater heterogeneity evident in $\beta$-cell function of patients with type 2 diabetes), recent findings of persistent $C$ peptide production and preserved $\beta$-cell function decades after diagnosis in distinct groups of patients may indicate inherent differences in populations with regard to the ability to tolerate stress in the $\beta$ cell (Wang et al. 2012).

Experimental lessons gleaned from the rare, deterministic UPR diabetic disorders, described in the last section, must be interpreted and applied cautiously to common human diabetes (both types 1 and 2), which occur heterogeneously and probabilistically, and after also carefully considering other disease factors that are likely at play. Because it evolved through the study of lower eukaryote models such as yeast, the study of signaling in the UPR and its physiological consequences is often confined and ascribed to cell-autonomous effects (Walter and Ron 2011). However, it is very likely that changes in cell-cell signaling caused by ER stress strongly impact inter-organ functioning in mammals. For instance, ER stress signaling in inflamed insulin-responsive target tissues such as liver and fat was shown to reduce insulin signaling (Ozcan et al. 2004); this should have the effect of increasing the burden for insulin production "at a distance" in $\beta$ cells.

Additionally, dysregulated UPR signaling in immune cells that neighbor $\beta$ cells in the islets may also be pathogenic. The secretory pathway is the gateway for the structural maturation of about one-third of the proteome; therefore, small changes in ER stress signaling and UPR outputs could have widespread effects. As immune cells operate through cell-surface receptors and soluble secreted proteins, UPR defects leading to immune cell dysfunction could conceivably promote loss of self-tolerance against $\beta$ cells. In addition, local inflammation in the islet from pro-inflammatory cytokines such as interleukin 1- $\beta$ (IL-1 $\beta$ ) released locally in the islet by cells of the innate immune system can adversely affect $\beta$-cell function (also see below); 
interestingly, a link between upstream ER stress and IL-1 $\beta$ was recently noted (Menu et al. 2012).

UPR studies are often performed with unnatural ER stress agents that deterministically push cells rapidly into apoptosis. More care should be given to studying subtle disease-relevant in vivo defects that develop over longer periods in murine models. Measuring ER stress in $\beta$ cells of living humans is currently not feasible, because the pancreatic islet $\beta$-cell mass and insulin secretory function during life cannot be studied simultaneously. However, pancreatic autopsy series from type 2 diabetic patients clearly show a reduction in $\beta$-cell mass (Yoon et al. 2003) concomitant with activation in UPR apoptotic markers. In addition, human type 2 diabetic islets contain protein aggregates in the form of amyloid (Westermark et al. 1992). Islet amyloid is composed of a 37-residue amyloidogenic polypeptide called islet amyloid polypeptide (IAPP). IAPP spontaneously forms ER membrane-damaging sheets of amyloid ( $\mathrm{Sa}$ waya et al. 2007). Therefore, IAPP could be another ER stress link promoting $\beta$-cell death through activation of the pro-apoptotic transcription factor CHOP (Huang et al. 2007).

Oxidative stress and inflammation engendered by ER stress may further drive a terminal UPR into a common terminal pathway leading to $\beta$-cell demise in both types 1 and 2 diabetes. Indeed, one recent study linked IAPP to production of pro-inflammatory $1 \mathrm{~L}-1 \beta$ by the NLRP3 inflammasome, a multiprotein complex that responds to internal danger signals (Masters et al. 2010). We propose a unified model that integrates oxidative and inflammatory damage as driving links and amplifiers for ER stress in the pathogenesis of common forms of human diabetes - types 1 and 2 (Fig. 4). Similarly, these principles could apply during gestation, during which increasing insulin requirements necessitate an approximate doubling of the $\beta$-cell mass in pregnant mothers (Karnik et al. 2007). In some individuals (perhaps those who are already at risk for DM2), this could increase risk for gestational diabetes (GDM) (Buchanan and Xiang 2005). Indeed, it is well appreciated that GDM puts affected mothers at risk for DM2 later in life, perhaps by reducing the existing baseline mass of $\beta$ cells after parturition.

\section{KEY COMPONENTS OF THE UPR APOPTOTIC SWITCH AND THERAPEUTIC STRATEGIES}

We turn now to a more rigorous and mechanistic review of how the UPR appears to switch from promoting homeostasis to instead causing cell destruction and apoptosis (see Fig. 5) (Merksamer and Papa 2010). We propose that many key components of this terminal UPR switch may pose attractive targets for drugging.

As mentioned above, the UPR is triggered by three ER-resident transmembrane proteins: PERK, ATF6, and IRE1 $\alpha$. The presence of unfolded ER proteins is thought to activate each of these three proximal detectors through direct and/or indirect sensing mechanisms (Kohno 2007). IRE $1 \alpha$ is a type-I transmembrane protein that contains three domains: an amino-terminal domain that resides in the ER lumen and senses unfolded proteins, a cytosolic serine/ threonine kinase domain, and a carboxy-terminal cytosolic endoribonuclease (RNase) domain (Tirasophon et al. 1998; Wang et al. 1998). IRE $1 \alpha$ becomes activated when monomers oligomerize into either dimers or higher-order oligomers, causing trans-autophosphorylation of the kinase domains, which, in turn, activates the RNase domains. Two opposing models have been proposed to explain how IRE1 $\alpha$ changes its oligomerization state. It has been suggested that the ER-resident chaperone immunoglobulin-binding protein ( $\mathrm{BiP}$ ) functions as a key regulator by binding to IRE $1 \alpha$ and inhibiting its oligomerization. When unfolded proteins accumulate, BiP dissociates from IRE1 $\alpha$ to preferentially engage and refold them, freeing up IRE1 $\alpha$ to oligomerize (Bertolotti et al. 2000). The second model proposes that unfolded proteins bind directly to the lumenal domain of IRE1 $\alpha$, which, in turn, induces its oligomerization (Credle et al. 2005; Gardner and Walter 2011). Structural data are lacking to definitively rule in (or rule out) each of the two models. Because PERK has an amino-terminal lumenal domain homologous to IRE1 $\alpha$, it is very likely to 
F.R. Papa
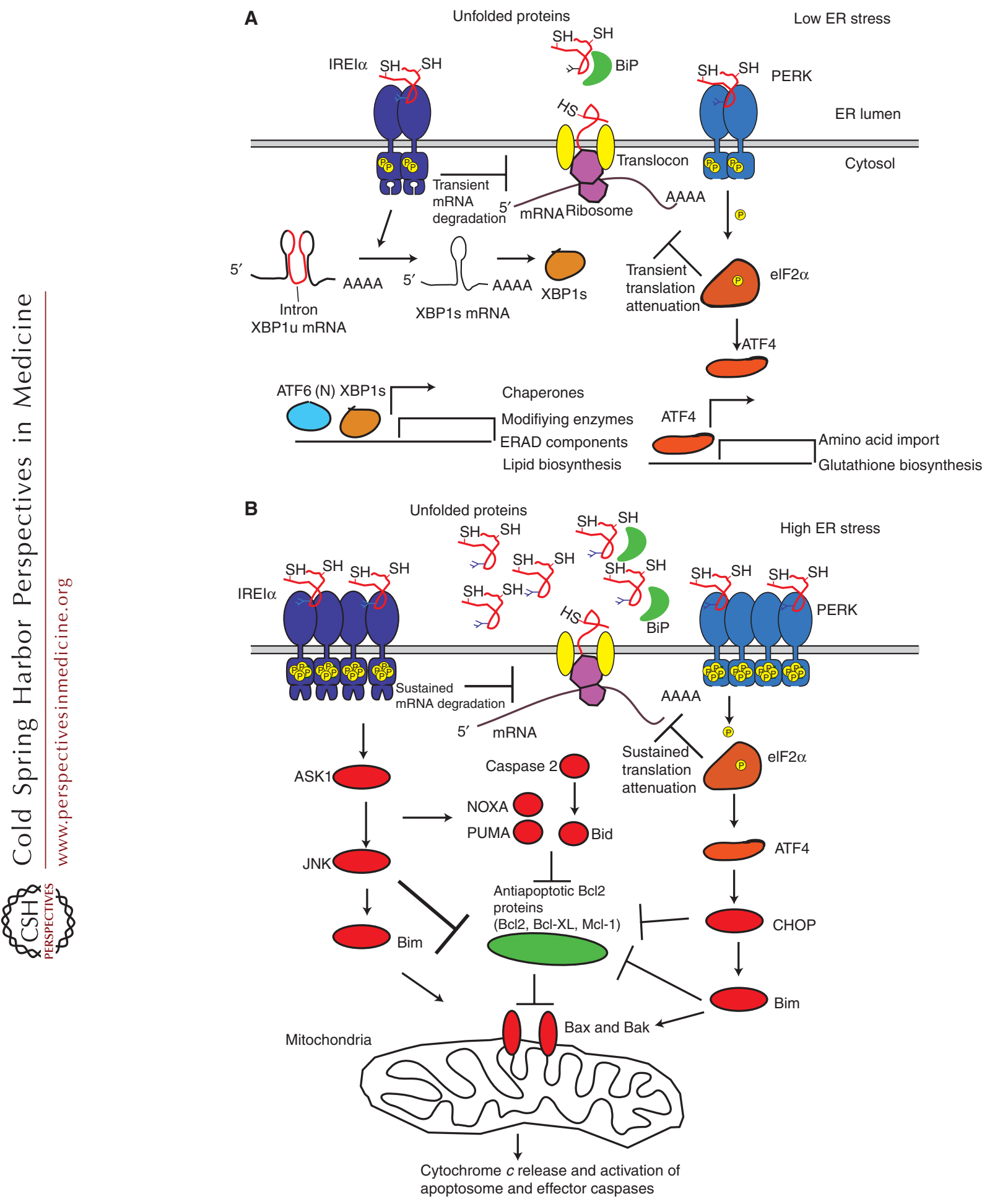

Figure 5. (See legend on facing page.) 
become activated by similar principles (Bertolotti et al. 2000; Liu et al. 2000).

A different mechanism governs ATF6 activation, which is an ER-resident type-II transmembrane protein that exists basally as an oxidized monomer, dimer, and/or oligomer associated with BiP. Under ER stress, ATF6 dissociates from BiP and conserved intramolecular and/ or intermolecular disulfide bonds in the lumenal domain of ATF6 become reduced. The resulting reduced ATF6 monomers translocate to the Golgi and become cleaved by the Site-1 and Site- 2 proteases (Haze et al. 1999; Shen et al. 2005; Nadanaka et al. 2007). This liberates the amino-terminal cytosolic fragment of ATF6, producing a soluble variant called ATF6(N), which is a basic leucine zipper (bZiP) transcription factor. ATF6(N) transcriptional targets appear to be largely adaptive because they include genes encoding chaperones as well as the mRNA encoding the adaptive XBP1 transcription factor (Yoshida et al. 2001, 2003; Rutkowski et al. 2006; Wu et al. 2007) (see below). The consequences of PERK and IRE1 $\alpha$ signaling, however, appear to be context and time dependent, and they lead to divergent cell fate outcomes based on these variables.

PERK and IRE1 $\alpha$ may operate as "stress integrators" that also use a time variable to determine if cells have crossed a threshold beyond which a different cell fate outcome is triggered. We have proposed that if adaptive outputs from PERK and IRE1 $\alpha$ succeed in reducing ER stress, homeostasis will be restored and the cell will be averted from downstream destructive outcomes. The adaptive responses through PERK and IRE1 $\alpha$ involve several outputs and can be conceptualized as two negative-feedback loops acting on two different time scales: a fast negative-feedback loop that rapidly decreases the influx of proteins into the ER; and a slow negative-feedback loop that requires de novo mRNA and protein synthesis to increase the folding capacity of the ER, and is therefore slower (Trusina et al. 2008). As shown in Figure 2 , the amplitude and/or strength of the perturbant stress is an additional variable that will determine if cells have crossed a cell fate-determining threshold (i.e., a strong stress requires less time than a weaker stress to push cells into apoptosis; conversely, weak stresses may build up over time to produce the same effect as a strong, short stress). Activated PERK phosphorylates eIF $2 \alpha$, which impedes subsequent rounds of translation initiation (Harding et al. 1999). In addition, IRE $1 \alpha$ rapidly degrades several hundred ER-localized mRNAs upon activation (Hollien and Weissman 2006; Han et al. 2009). Transient translation attenuation (through PERK) and mRNA decay (through IRE1 $\alpha$ ) should constitute a fast negative-feedback loop because together they should rapidly reduce the protein load on the ER. This provides the ER's folding machinery an extended opportunity to fold existing unfolded proteins and the ERAD machinery an extended time period to degrade them.

Additionally, both PERK and IRE1 $\alpha$ have synthetic outputs, which also work as slower negative-feedback loops. For instance, although PERK activation inhibits cap-dependent translation, some mRNAs having small upstream open reading frames (uORFs) become preferentially translated during this block. For example, as mentioned earlier, the pro-survival transcription factor ATF4 has a target set that includes activities that attenuate oxidative stress (Harding et al. 2000a). The synthetic output of IRE1 $\alpha$ occurs when it catalyzes the unconventional splicing of XBP1u mRNA into XBP1s

Figure 5. (Continued) Molecular details of the UPR homeostatic-apoptotic switch. (A) adaptive UPR events reduce protein load acutely through reversible translational attenuation and mRNA decay (mediated by PERK and IRE1 $\alpha$, respectively). Synthesis of gene products through de novo transcription/translation enhances ER protein-folding functions and ER-associated degradation (ERAD). (B) The terminal UPR occurs when ER unfolded proteins cannot be sufficiently reduced, and therefore UPR sensor signaling is not quelled. In that instance, destructive UPR outputs occur through continued IRE1 $\alpha$ mRNA endonucleolytic decay and continued translational blocks through PERK. Downstream amplification of the terminal UPR occurs through JNK and CHOP impinging on Bax and Bak to promote MOMP. 
F.R. Papa

mRNA, which encodes the bZIP transcription factor X-box-binding protein 1 (XBP1s) (Yoshida et al. 2001; Calfon et al. 2002). ATF6(N) and $\mathrm{XBP} 1 \mathrm{~s}$ work together to increase transcription rates of genes encoding ER-resident chaperones, protein-modification enzymes, ERAD components, and lipid biosynthetic enzymes to augment ER size and to increase the ER's folding and degradation activities (Yamamoto et al. 2007). Collectively, these negative-feedback loops should reduce the concentration of unfolded proteins in the ER, and as the concentration of unfolded proteins decreases, the UPR shuts off.

The conversion of adaptive UPR signaling into destruction may occur as the negative-feedback loops collapse and morph into feed-forward destructive loops under high ER stress (lower panel of Fig. 5). Events heralding this conversion include transcription of the late ATF4 target, the pro-apoptotic transcription factor CHOP. That CHOP is clearly an important mediator between the UPR and the apoptotic machinery was shown by protection of Chop ${ }^{-/-}$ mice against ER-stress-induced $\beta$-cell apoptosis in several experimental models of diabetes (Song et al. 2008). Another definitive step marking entry into apoptosis occurs when the outer mitochondrial membrane (OMM) is permeabilized and cytochrome $c$ is released to activate executioner caspases-designated MOMP (Shore et al. 2011). This intrinsic (mitochondrial) apoptotic pathway is typically triggered in response to intracellular stresses including DNA damage and viral infections and is regulated by the Bcl-2 protein family (Youle and Strasser 2008).

The Bcl-2 family is divided into three groups: multidomain pro-apoptotic proteins (e.g., BAX, BAK), anti-apoptotic proteins (e.g., BCL-2, BCL-XL), and pro-apoptotic $\mathrm{BH} 3$-only proteins (e.g., BID, BAD, BIM, NOXA, PUMA) (Brunelle and Letai 2009). In response to ER stress, the pro-apoptotic $\mathrm{BH} 3$-only proteins are transcriptionally or posttranslationally activated to stimulate pro-apoptotic BAX and BAK either directly or indirectly through antagonizing anti-apoptotic members. Once activated, BAX and/or BAK form homo-oligomers in the OMM to initiate MOMP (Wei et al. 2001). Of the BH3only family, PUMA, NOXA, BID, and BIM have been implicated in apoptosis triggered by ER stress (Li et al. 2006; Puthalakath et al. 2007; Upton et al. 2008). Moreover, the adaptor protein CRK has recently been shown to contain a "BH3-like" domain that undergoes proteolytic processing under ER stress and is required for efficient ER stress-induced apoptosis (Austgen et al. 2012). CHOP mRNA levels increase sharply during a terminal UPR through up-regulation by the transcription factor ATF4 downstream from PERK and eIF2 $\alpha$. Providing an important link between the terminal UPR and a $\mathrm{BH} 3$-only protein, CHOP increases Bim transcription during ER stress (Puthalakath et al. 2007). In addition to regulating Bim expression, $\mathrm{CHOP}$ antagonizes the expression of anti-apoptotic Bcl-2.

Another terminal UPR component may be the mitogen-activated protein kinase (MAPK) c-Jun amino-terminal kinase (JNK) operating downstream from IRE1 $\alpha$ and in parallel with the PERK-ATF4-CHOP arm. JNK is activated by cytokines and several intracellular stresses and can promote apoptosis when hyperactivated (Weston and Davis 2007). JNK signaling increases downstream from IRE1 $\alpha$, the tumor necrosis factor receptor-associated factor 2 (TRAF2), and the MAP3K apoptosis signal-regulating kinase 1 (ASK1) (Urano et al. 2000; Nishitoh et al. 2002). JNK may promote apoptosis by interacting with Bcl-2 family members; specifically, JNK may phosphorylate and inhibit the anti-apoptotic proteins BCL-2, BCL-XL, and MCL-1. Furthermore, JNK can also phosphorylate and activate several $\mathrm{BH}-3$ only proteins, including BID and BIM to promote apoptosis (Weston and Davis 2007).

Because the UPR simultaneously transmits survival and apoptotic outputs, understanding the interplay between these competing signals is necessary to elucidate the mechanism by which cells decide whether to continue to attempt adaptation or to initiate cell death. We have proposed that tonic high-level activation of both PERK and IRE1 $\alpha$ will signal an inability to adapt and initiate the aforementioned destructive outputs. In support of this notion experimentally, overexpression of either PERK or 
IRE1 $\alpha$, which leads to their spontaneous oligomerization and activation, is typically sufficient to cause apoptosis. Intertwining with the Bcl-2 family, sustained PERK activity may be necessary to build CHOP levels to a required threshold to stimulate $\mathrm{Bcl}-2$ proteins to commit to apoptosis. In addition, sustained PERK activity should result in protracted translation attenuation, which would be incompatible with cell survival. Similarly, sustained mRNA degradation mediated by hyperactivated IRE1 $\alpha$ may deplete ER cargo and protein-folding activities (Han et al. 2009). This last point may have further significance for $\beta$-cell degeneration in that degradation of insulin mRNA during high ER stress by IRE $1 \alpha$ in any one $\beta$ cell, as we and others have shown (Pirot et al. 2007; Lipson et al. 2008; Han et al. 2009), should simply shift the burden of insulin production to another $\beta$ cell, thereby promoting organ failure. This may occur as whole-scale mRNA decay by IRE1 $\alpha$ at the ER membrane consumes the very mRNAs encoding the very same activities needed to salvage ER function (chaperones, oxidoreductases, etc.).

We conclude this review by highlighting some select UPR targets that could be modulated to bias toward cell survival. We propose that UPR components present rich and attractive targets for pharmacological intervention. However, the parallel and cross-wired networks may require several nodes to be targeted simultaneously to effect robust therapeutic effects. Nevertheless, for cell degenerative diseases such as diabetes, the biasing of the UPR homeostaticapoptotic switch to favor cell survival could potentially be disease-modifying, thus payoffs may be large. One strategy is to prolong the adaptive phases of the UPR to maximize chances of recovery (examples of such targets would include XBP1 and ATF6). Another route would be to inhibit key mediators of apoptosis (CHOP, BAX, BAK). Related to this, the strategy of preconditioning by preemptive adaptive UPR activation could be beneficial. Potential timers such as $\mathrm{p} 58^{\mathrm{IPK}}$ may also pose attractive targets. Indeed, a small molecule called salubrinal was shown to block phosphatases mediating eIF $2 \alpha$ dephosphorylation to enhance cell survival under ER stress (Boyce et al. 2005).
Similarly, preemptive activation of the kinase PERK was shown through a proof-of-concept strategy (using synthetic dimerizable modules) to enhance survival in cell culture models of ER and oxidative stress (Lu et al. 2004). It is unclear, however, whether long-term PERK activation with its attendant consequences of inhibiting translation could be a viable strategy for cytoprotection in vivo. In addition, we (Han et al. 2008) and others (Lin et al. 2007) have shown that IRE1 $\alpha$ activation can prolong survival under ER stress. The basis for this particular strategy rests on a highly unusual relationship between IRE1 $\alpha$ 's two catalytic domains that we discovered (Papa et al. 2003). We showed that the kinase of IRE1 $\alpha$ can be engaged with a designer kinase inhibitor to trigger RNase activity and force splicing of the XBP1 mRNA, leading to production of the pro-survival XBP1s transcription factor, while bypassing the kinase activity. Cells subjected to these maneuvers preemptively enjoy a small, but significant, measure of cytoprotection when they are challenged by ER stress (Han et al. 2008). However, kinaseactive versions of IRE $1 \alpha$ that become hyperactivated in their RNase domain cause massive endonucleolytic degradation of mRNAs localizing to the ER membrane during cotranslational translocation of protein products (Han et al. 2009). This event was shown to push cells into a terminal UPR. Inhibition of the RNase domains by small-molecule direct inhibitors may be therapeutic in these contexts (Papandreou et al. 2010).

Finally, it has been shown that small chemical chaperones that could act as templates for protein folding and that may have global effects on stabilizing protein conformations also afford significant protection, directly in animals, to forestall diabetes (Ozcan et al. 2006).

In conclusion, ER stress and its remediation in pancreatic $\beta$ cells, as a set of related topics, will continue to attract attention from experts in fields ranging from cell biology to pathology, signal transduction, epidemiology, pharmacology, and medicine. We predict that the next few years will bring many more challenges, as well as opportunities for discovery and invention. 
F.R. Papa

\section{REFERENCES}

Austgen K, Johnson ET, Park TJ, Curran T, Oakes SA. 2012. The adaptor protein CRK is a pro-apoptotic transducer of endoplasmic reticulum stress. Nat Cell Biol 14: 87-92.

Bernales S, Papa FR, Walter P. 2006. Intracellular signaling by the unfolded protein response. Annu Rev Cell Dev Biol 22: $487-508$.

Bertolotti A, Zhang Y, Hendershot LM, Harding HP, Ron D. 2000. Dynamic interaction of BiP and ER stress transducers in the unfolded-protein response. Nat Cell Biol 2: $326-332$.

Boyce M, Bryant KF, Jousse C, Long K, Harding HP, Scheuner D, Kaufman RJ, Ma D, Coen DM, Ron D, et al. 2005. A selective inhibitor of eIF $2 \alpha$ dephosphorylation protects cells from ER stress. Science 307: 935-939.

Brunelle JK, Letai A. 2009. Control of mitochondrial apoptosis by the Bcl-2 family. J Cell Sci 122: 437-441.

Buchanan TA, Xiang AH. 2005. Gestational diabetes mellitus. J Clin Invest 115: 485-491.

Calfon M, Zeng H, Urano F, Till JH, Hubbard SR, Harding HP, Clark SG, Ron D. 2002. IRE1 couples endoplasmic reticulum load to secretory capacity by processing the XBP-1 mRNA. Nature 415: 92-96.

Credle JJ, Finer-Moore JS, Papa FR, Stroud RM, Walter P. 2005. On the mechanism of sensing unfolded protein in the endoplasmic reticulum. Proc Natl Acad Sci 102: 18773-18784.

Delepine M, Nicolino M, Barrett T, Golamaully M, Lathrop GM, Julier C. 2000. EIF2AK3, encoding translation initiation factor $2-\alpha$ kinase 3 , is mutated in patients with Wolcott-Rallison syndrome. Nat Genet 25: 406-409.

Ding Y, Yamada S, Wang KY, Shimajiri S, Guo X, Tanimoto A, Murata Y, Kitajima S, Watanabe T, Izumi H, et al. 2010. Overexpression of peroxiredoxin 4 protects against highdose streptozotocin-induced diabetes by suppressing oxidative stress and cytokines in transgenic mice. Antioxid Redox Signal 13: 1477-1490.

Fonseca SG, Fukuma M, Lipson KL, Nguyen LX, Allen JR, Oka Y, Urano F. 2005. WFS1 is a novel component of the unfolded protein response and maintains homeostasis of the endoplasmic reticulum in pancreatic $\beta$-cells. J Biol Chem 280: 39609-39615.

Fonseca SG, Ishigaki S, Oslowski CM, Lu S, Lipson KL, Ghosh R, Hayashi E, Ishihara H, Oka Y, Permutt MA, et al. 2010. Wolfram syndrome 1 gene negatively regulates ER stress signaling in rodent and human cells. J Clin Invest 120: 744-755.

Gardner BM, Walter P. 2011. Unfolded proteins are Ire1activating ligands that directly induce the unfolded protein response. Science 333: 1891-1894.

Gaut JR, Hendershot LM. 1993. The modification and assembly of proteins in the endoplasmic reticulum. Curr Opin Cell Biol 5: 589-595.

Gething M-J, Sambrook J. 1992. Protein folding in the cell. Nature 355: 33-45.

Gupta S, McGrath B, Cavener DR. 2009. PERK regulates the proliferation and development of insulin-secreting $\beta$-cell tumors in the endocrine pancreas of mice. PLOS ONE 4: e8008.
Han D, Upton JP, Hagen A, Callahan J, Oakes SA, Papa FR 2008. A kinase inhibitor activates the IRE $1 \alpha$ RNase to confer cytoprotection against ER stress. Biochem Biophys Res Commun 365: 777-783.

Han D, Lerner AG, Vande Walle L, Upton JP, Xu W, Hagen A, Backes BJ, Oakes SA, Papa FR. 2009. IRE1 $\alpha$ kinase activation modes control alternate endoribonuclease outputs to determine divergent cell fates. Cell 138: 562-575.

Harding HP, Zhang Y, Ron D. 1999. Protein translation and folding are coupled by an endoplasmic-reticulum-resident kinase. Nature 397: 271-274.

Harding HP, Novoa I, Zhang Y, Zeng H, Wek R, Schapira M, Ron D. 2000a. Regulated translation initiation controls stress-induced gene expression in mammalian cells. Mol Cell 6: 1099-1108.

Harding HP, Zhang Y, Bertolotti A, Zeng H, Ron D. 2000b. Perk is essential for translational regulation and cell survival during the unfolded protein response. Mol Cell 5: 897-904.

Haze K, Yoshida H, Yanagi H, Yura T, Mori K. 1999. Mammalian transcription factor ATF6 is synthesized as a transmembrane protein and activated by proteolysis in response to endoplasmic reticulum stress. Mol Biol Cell 10: 3787-3799.

Hollien J, Weissman JS. 2006. Decay of endoplasmic reticulum-localized mRNAs during the unfolded protein response. Science 313: 104-107.

Huang CJ, Lin CY, Haataja L, Gurlo T, Butler AE, Rizza RA, Butler PC. 2007. High expression rates of human islet amyloid polypeptide induce endoplasmic reticulum stress-mediated $\beta$-cell apoptosis, a characteristic of humans with type 2 but not type 1 diabetes. Diabetes 56: 2016-2027.

Iwawaki T, Akai R, Kohno K, Miura M. 2004. A transgenic mouse model for monitoring endoplasmic reticulum stress. Nat Med 10: 98-102.

Izumi T, Yokota-Hashimoto H, Zhao S, Wang J, Halban PA, Takeuchi T. 2003. Dominant negative pathogenesis by mutant proinsulin in the Akita diabetic mouse. Diabetes 52: $409-416$.

Kaniuk NA, Kiraly M, Bates H, Vranic M, Volchuk A, Brumell JH. 2007. Ubiquitinated-protein aggregates form in pancreatic $\beta$-cells during diabetes-induced oxidative stress and are regulated by autophagy. Diabetes 56: 930-939.

Karam JH, Grodsky GM, Forsham PH. 1963. Excessive insulin response to glucose in obese subjects as measured by immunochemical assay. Diabetes 12: 197-204.

Karnik SK, Chen H, McLean GW, Heit JJ, Gu X, Zhang AY, Fontaine M, Yen MH, Kim SK. 2007. Menin controls growth of pancreatic $\beta$-cells in pregnant mice and promotes gestational diabetes mellitus. Science 318: 806809.

Kaufman RJ. 2002. Orchestrating the unfolded protein response in health and disease. J Clin Invest 110: 13891398.

Knowler WC, Barrett-Connor E, Fowler SE, Hamman RF, Lachin JM, Walker EA, Nathan DM. 2002. Reduction in the incidence of type 2 diabetes with lifestyle intervention or metformin. N Engl J Med 346: 393-403. 
Kohno K. 2007. How transmembrane proteins sense endoplasmic reticulum stress. Antioxid Redox Signal 9: 22952303.

Ladiges WC, Knoblaugh SE, Morton JF, Korth MJ, Sopher BL, Baskin CR, MacAuley A, Goodman AG, LeBoeuf RC Katze MG. 2005. Pancreatic $\beta$-cell failure and diabetes in mice with a deletion mutation of the endoplasmic reticulum molecular chaperone gene P58IPK. Diabetes 54: 1074-1081.

Laybutt DR, Preston AM, Akerfeldt MC, Kench JG, Busch AK, Biankin AV, Biden TJ. 2007. Endoplasmic reticulum stress contributes to $\beta$ cell apoptosis in type 2 diabetes. Diabetologia 50: 752-763.

Lenzen S, Drinkgern J, Tiedge M. 1996. Low antioxidant enzyme gene expression in pancreatic islets compared with various other mouse tissues. Free Radic Biol Med 20: $463-466$.

Li J, Lee B, Lee AS. 2006. Endoplasmic reticulum stressinduced apoptosis: Multiple pathways and activation of p53-Up-regulated modulator of apoptosis (PUMA) and NOXA by p53. J Biol Chem 281: 7260-7270.

Lin JH, Li H, Yasumura D, Cohen HR, Zhang C, Panning B, Shokat KM, LaVail MM, Walter P. 2007. IRE1 signaling affects cell fate during the unfolded protein response. Science 318: 944-949.

Lipson KL, Ghosh R, Urano F. 2008. The role of IRE1 $\alpha$ in the degradation of insulin mRNA in pancreatic $\beta$-cells. PLoS ONE 3: e1648.

Liu CY, Schroder M, Kaufman RJ. 2000. Ligand-independent dimerization activates the stress response kinases IRE1 and PERK in the lumen of the endoplasmic reticulum. J Biol Chem 275: 24881-24885.

Liu M, Li Y, Cavener D, Arvan P. 2005. Proinsulin disulfide maturation and misfolding in the endoplasmic reticulum. J Biol Chem 280: 13209-13212.

Lu PD, Jousse C, Marciniak SJ, Zhang Y, Novoa I, Scheuner D, Kaufman RJ, Ron D, Harding HP. 2004. Cytoprotection by pre-emptive conditional phosphorylation of translation initiation factor 2. EMBO J 23: 169-179.

Masters SL, Dunne A, Subramanian SL, Hull RL, Tannahill GM, Sharp FA, Becker C, Franchi L, Yoshihara E, Chen Z, et al. 2010. Activation of the NLRP3 inflammasome by islet amyloid polypeptide provides a mechanism for enhanced IL-1 $\beta$ in type 2 diabetes. Nat Immunol 11: 897-904.

McCracken AA, Brodsky JL. 2003. Evolving questions and paradigm shifts in endoplasmic-reticulum-associated degradation (ERAD). Bioessays 25: 868-877.

Menu P, Mayor A, Zhou R, Tardivel A, Ichijo H, Mori K, Tschopp J. 2012. ER stress activates the NLRP3 inflammasome via an UPR-independent pathway. Cell Death Dis 3: e261.

Merksamer PI, Papa FR. 2010. The UPR and cell fate at a glance. J Cell Sci 123: 1003-1006.

Merksamer PI, Trusina A, Papa FR. 2008. Real-time redox measurements during endoplasmic reticulum stress reveal interlinked protein folding functions. Cell 135: 933-947.

Meusser B, Hirsch C, Jarosch E, Sommer T. 2005. ERAD: The long road to destruction. Nat Cell Biol 7: 766-772.
Nadanaka S, Okada T, Yoshida H, Mori K. 2007. Role of disulfide bridges formed in the lumenal domain of ATF6 in sensing endoplasmic reticulum stress. Mol Cell Biol 27: 1027-1043.

Nishitoh H, Matsuzawa A, Tobiume K, Saegusa K, Takeda K, Inoue K, Hori S, Kakizuka A, Ichijo H. 2002. ASK1 is essential for endoplasmic reticulum stress-induced neuronal cell death triggered by expanded polyglutamine repeats. Genes Dev 16: 1345-1355.

Oyadomari S, Koizumi A, Takeda K, Gotoh T, Akira S, Araki E, Mori M. 2002. Targeted disruption of the Chop gene delays endoplasmic reticulum stress-mediated diabetes. J Clin Invest 109: 525-532.

Oyadomari S, Yun C, Fisher EA, Kreglinger N, Kreibich G, Oyadomari M, Harding HP, Goodman AG, Harant H, Garrison JL, et al. 2006. Cotranslocational degradation protects the stressed endoplasmic reticulum from protein overload. Cell 126: 727-739.

Ozcan U, Cao Q, Yilmaz E, Lee AH, Iwakoshi NN, Ozdelen E, Tuncman G, Gorgun C, Glimcher LH, Hotamisligil GS. 2004. Endoplasmic reticulum stress links obesity, insulin action, and type 2 diabetes. Science 306: 457-461.

Ozcan U, Yilmaz E, Ozcan L, Furuhashi M, Vaillancourt E, Smith RO, Gorgun CZ, Hotamisligil GS. 2006. Chemical chaperones reduce ER stress and restore glucose homeostasis in a mouse model of type 2 diabetes. Science 313: 1137-1140.

Papa FR, Zhang C, Shokat K, Walter P. 2003. Bypassing a kinase activity with an ATP-competitive drug. Science 302: $1533-1537$.

Papandreou I, Denko NC, Olson M, Van Melckebeke H, Lust S, Tam A, Solow-Cordero DE, Bouley DM, Offner F, Niwa $\mathrm{M}$, et al. 2010. Identification of an Ire1 $\alpha$ endonuclease specific inhibitor with cytotoxic activity against human multiple myeloma. Blood 117: 1311-1314.

Pirot P, Naamane N, Libert F, Magnusson NE, Orntoft TF, Cardozo AK, Eizirik DL. 2007. Global profiling of genes modified by endoplasmic reticulum stress in pancreatic $\beta$ cells reveals the early degradation of insulin mRNAs. $D i$ abetologia 50: 1006-1014.

Puthalakath H, O’Reilly LA, Gunn P, Lee L, Kelly PN, Huntington ND, Hughes PD, Michalak EM, McKimmBreschkin J, Motoyama N, et al. 2007. ER stress triggers apoptosis by activating BH3-only protein Bim. Cell 129: 1337-1349.

Reimold AM, Iwakoshi NN, Manis J, Vallabhajosyula P, Szomolanyi-Tsuda E, Gravallese EM, Friend D, Grusby MJ, Alt F, Glimcher LH. 2001. Plasma cell differentiation requires the transcription factor XBP-1. Nature 412: $300-$ 307.

Riggs AC, Bernal-Mizrachi E, Ohsugi M, Wasson J, Fatrai S, Welling C, Murray J, Schmidt RE, Herrera PL, Permutt MA. 2005. Mice conditionally lacking the Wolfram gene in pancreatic islet $\beta$ cells exhibit diabetes as a result of enhanced endoplasmic reticulum stress and apoptosis. Diabetologia 48: 2313-2321.

Ron D. 2002. Proteotoxicity in the endoplasmic reticulum: Lessons from the Akita diabetic mouse. J Clin Invest 109: 443-445.

Rutkowski DT, Arnold SM, Miller CN, Wu J, Li J, Gunnison KM, Mori K, Sadighi Akha AA, Raden D, Kaufman RJ. 2006. Adaptation to ER stress is mediated by differential 
F.R. Papa

stabilities of pro-survival and pro-apoptotic mRNAs and proteins. PLoS Biol 4: e374.

Sawaya MR, Sambashivan S, Nelson R, Ivanova MI, Sievers SA, Apostol MI, Thompson MJ, Balbirnie M, Wiltzius JJ, McFarlane HT, et al. 2007. Atomic structures of amyloid cross- $\beta$ spines reveal varied steric zippers. Nature 447: 453-457.

Scheuner D, Kaufman RJ. 2008. The unfolded protein response: A pathway that links insulin demand with $\beta$-cell failure and diabetes. Endocr Rev 29: 317-333.

Scheuner D, Song B, McEwen E, Liu C, Laybutt R, Gillespie P, Saunders T, Bonner-Weir S, Kaufman RJ. 2001. Translational control is required for the unfolded protein response and in vivo glucose homeostasis. Mol Cell 7: 1165-1176.

Scheuner D, Vander Mierde D, Song B, Flamez D, Creemers JW, Tsukamoto K, Ribick M, Schuit FC, Kaufman RJ. 2005. Control of mRNA translation preserves endoplasmic reticulum function in $\beta$ cells and maintains glucose homeostasis. Nat Med 11: 757-764.

Sevier CS, Kaiser CA. 2002. Formation and transfer of disulphide bonds in living cells. Nat Rev Mol Cell Biol 3: 836-847.

Shen J, Snapp EL, Lippincott-Schwartz J, Prywes R. 2005. Stable binding of ATF6 to BiP in the endoplasmic reticulum stress response. Mol Cell Biol 25: 921-932.

Shore GC, Papa FR, Oakes SA. 2011. Signaling cell death from the endoplasmic reticulum stress response. Curr Opin Cell Biol 23: 143-149.

Smith MH, Ploegh HL, Weissman JS. 2011. Road to ruin: Targeting proteins for degradation in the endoplasmic reticulum. Science 334: 1086-1090.

Song B, Scheuner D, Ron D, Pennathur S, Kaufman RJ. 2008. Chop deletion reduces oxidative stress, improves $\beta$ cell function, and promotes cell survival in multiple mouse models of diabetes. J Clin Invest 118: 3378-3389.

Stefan Y, Orci L, Malaisse-Lagae F, Perrelet A, Patel Y, Unger RH. 1982. Quantitation of endocrine cell content in the pancreas of nondiabetic and diabetic humans. Diabetes 31: 694-700.

Steiner DF. 2000. New aspects of proinsulin physiology and pathophysiology. J Pediatr Endocrinol Metab 13: 229-239.

Stoy J, Edghill EL, Flanagan SE, Ye H, Paz VP, Pluzhnikov A, Below JE, Hayes MG, Cox NJ, Lipkind GM, et al. 2007. Insulin gene mutations as a cause of permanent neonatal diabetes. Proc Natl Acad Sci 104: 15040-15044.

Tirasophon W, Welihinda AA, Kaufman RJ. 1998. A stress response pathway from the endoplasmic reticulum to the nucleus requires a novel bifunctional protein kinase/endoribonuclease (Irelp) in mammalian cells. Genes Dev 12: $1812-1824$.

Travers KJ, Patil CK, Wodicka L, Lockhart DJ, Weissman JS, Walter P. 2000. Functional and genomic analyses reveal an essential coordination between the unfolded protein response and ER-associated degradation. Cell 101: 249258.

Trusina A, Papa FR, Tang C. 2008. Rationalizing translation attenuation in the network architecture of the unfolded protein response. Proc Natl Acad Sci 105: 20280-20285.
Tu BP, Weissman JS. 2004. Oxidative protein folding in eukaryotes: Mechanisms and consequences. J Cell Biol 164: 341-346.

Upton JP, Austgen K, Nishino M, Coakley KM, Hagen A, Han D, Papa FR, Oakes SA. 2008. Caspase-2 cleavage of BID is a critical apoptotic signal downstream of endoplasmic reticulum stress. Mol Cell Biol 28: 3943-3951.

Urano F, Wang X, Bertolotti A, Zhang Y, Chung P, Harding HP, Ron D. 2000. Coupling of stress in the ER to activation of JNK protein kinases by transmembrane protein kinase IRE1. Science 287: 664-666.

Walter P, Ron D. 2011. The unfolded protein response: From stress pathway to homeostatic regulation. Science 334: 1081-1086.

Wang XZ, Harding HP, Zhang Y, Jolicoeur EM, Kuroda M, Ron D. 1998. Cloning of mammalian Ire1 reveals diversity in the ER stress responses. EMBO J 17: 5708-5717.

Wang J, Takeuchi T, Tanaka S, Kubo SK, Kayo T, Lu D, Takata K, Koizumi A, Izumi T. 1999. A mutation in the insulin 2 gene induces diabetes with severe pancreatic $\beta$-cell dysfunction in the Mody mouse. J Clin Invest 103: 27-37.

Wang L, Lovejoy NF, Faustman DL. 2012. Persistence of prolonged C-peptide production in type 1 diabetes as measured with an ultrasensitive C-peptide assay. Diabetes Care 35: 465-470.

Wei MC, Zong WX, Cheng EH, Lindsten T, Panoutsakopoulou V, Ross AJ, Roth KA, MacGregor GR, Thompson CB, Korsmeyer SJ. 2001. Proapoptotic BAX and BAK: A requisite gateway to mitochondrial dysfunction and death. Science 292: 727-730.

Weir GC, Bonner-Weir S. 2004. Five stages of evolving $\beta$-cell dysfunction during progression to diabetes. Diabetes 53: S16-S21.

Westermark P, Johnson KH, O’Brien TD, Betsholtz C. 1992. Islet amyloid polypeptide-A novel controversy in diabetes research. Diabetologia 35: 297-303.

Weston CR, Davis RJ. 2007. The JNK signal transduction pathway. Curr Opin Cell Biol 19: 142-149.

Wu J, Rutkowski DT, Dubois M, Swathirajan J, Saunders T, Wang J, Song B, Yau GD, Kaufman RJ. 2007. ATF6 $\alpha$ optimizes long-term endoplasmic reticulum function to protect cells from chronic stress. Dev Cell 13: 351-364.

Yamamoto K, Sato T, Matsui T, Sato M, Okada T, Yoshida H, Harada A, Mori K. 2007. Transcriptional induction of mammalian ER quality control proteins is mediated by single or combined action of ATF6 $\alpha$ and XBP1. Dev Cell 13: $365-376$.

Yoon KH, Ko SH, Cho JH, Lee JM, Ahn YB, Song KH, Yoo SJ, Kang MI, Cha BY, Lee KW, et al. 2003. Selective $\beta$-cell loss and $\alpha$-cell expansion in patients with type 2 diabetes mellitus in Korea. J Clin Endocrinol Metab 88: 2300-2308.

Yorimitsu T, Klionsky DJ. 2007. Eating the endoplasmic reticulum: Quality control by autophagy. Trends Cell Biol 17: 279-285.

Yoshida H, Okada T, Haze K, Yanagi H, Yura T, Negishi M, Mori K. 2000. ATF6 activated by proteolysis binds in the presence of NF-Y (CBF) directly to the cis-acting element responsible for the mammalian unfolded protein response. Mol Cell Biol 20: 6755-6767.

Yoshida H, Matsui T, Yamamoto A, Okada T, Mori K. 2001. XBP1 mRNA is induced by ATF6 and spliced by IRE1 in 
response to ER stress to produce a highly active transcription factor. Cell 107: 881-891.

Yoshida H, Matsui T, Hosokawa N, Kaufman RJ, Nagata K, Mori K. 2003. A time-dependent phase shift in the mammalian unfolded protein response. Dev Cell 4: 265271.

Youle RJ, Strasser A. 2008. The BCL-2 protein family: Opposing activities that mediate cell death. Nat Rev Mol Cell Biol 9: 47-59.

Zhang K, Shen X, Wu J, Sakaki K, Saunders T, Rutkowski DT, Back SH, Kaufman RJ. 2006. Endoplasmic reticulum stress activates cleavage of CREBH to induce a systemic inflammatory response. Cell 124: 587-599.

Zhou J, Liu CY, Back SH, Clark RL, Peisach D, Xu Z, Kaufman RJ. 2006. The crystal structure of human IRE1 luminal domain reveals a conserved dimerization interface required for activation of the unfolded protein response. Proc Natl Acad Sci 103: 14343-14348.

Zito E, Melo EP, Yang Y, Wahlander A, Neubert TA, Ron D. 2010. Oxidative protein folding by an endoplasmic reticulum-localized peroxiredoxin. Mol Cell 40: 787797. 


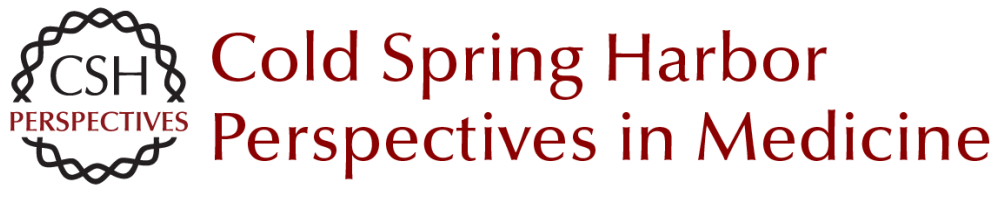

\section{Endoplasmic Reticulum Stress, Pancreatic $\beta$-Cell Degeneration, and Diabetes}

Feroz R. Papa

Cold Spring Harb Perspect Med 2012; doi: 10.1101/cshperspect.a007666 originally published online August 14, 2012

Subject Collection Type I Diabetes

The Pathogenesis and Natural History of Type 1

Diabetes

Mark A. Atkinson

Do MHCII-Presented Neoantigens Drive Type 1 Diabetes and Other Autoimmune Diseases? Philippa Marrack and John W. Kappler

Clinical Immunologic Interventions for the

Treatment of Type 1 Diabetes Lucienne Chatenoud, Katharina Warncke and Anette-G. Ziegler

Update on Islet Transplantation Michael McCall and A.M. James Shapiro

Immunologic and Metabolic Biomarkers of $\beta$-Cell

Destruction in the Diagnosis of Type 1 Diabetes Jasmin Lebastchi and Kevan C. Herold

Advancing Animal Models of Human Type 1

Diabetes by Engraftment of Functional Human

Tissues in Immunodeficient Mice Michael A. Brehm, Alvin C. Powers, Leonard D. Shultz, et al.

Breakdown in Peripheral Tolerance in Type 1

Diabetes in Mice and Humans Lukas T. Jeker, Hélène Bour-Jordan and Jeffrey A. Bluestone

Antigen-Specific Therapeutic Approaches in Type 1 Diabetes Xavier Clemente-Casares, Sue Tsai, Carol Huang, et al.
Humoral Autoimmunity in Type 1 Diabetes:

Prediction, Significance, and Detection of Distinct Disease Subtypes

Massimo Pietropaolo, Roberto Towns and George S. Eisenbarth

Endoplasmic Reticulum Stress, Pancreatic $\beta$-Cell Degeneration, and Diabetes Feroz R. Papa

Islet Autoantigens: Structure, Function, Localization, and Regulation Peter Arvan, Massimo Pietropaolo, David Ostrov, et al.

Environmental Triggers of Type 1 Diabetes Mikael Knip and Olli Simell

Generating $\beta$ Cells from Stem Cells--The Story So Far Matthias Hebrok

Antigen Targets of Type 1 Diabetes Autoimmunity Bart O. Roep and Mark Peakman

Connecting Type 1 and Type 2 Diabetes through Innate Immunity Justin I. Odegaard and Ajay Chawla

The Hygiene Hypothesis: An Explanation for the Increased Frequency of Insulin-Dependent Diabetes Jean-François Bach and Lucienne Chatenoud

For additional articles in this collection, see http://perspectivesinmedicine.cshlp.org/cgi/collection/ 